http://jmscr.igmpublication.org/home/ ISSN (e)-2347-176x ISSN (p) 2455-0450 crossref DOI: https://dx.doi.org/10.18535/jmscr/v7i8.86

\title{
Serum cytokines are related to oxidative stress in Nigerian patients with Parkinson's disease
}

Authors

\author{
Kazeem Adebayo Oderinu ${ }^{1 *}$, Olabamiji Abiodun Ajose², Lateef Salawu', \\ Morenikeji Adeyoyin Komolafe ${ }^{4}$, Falilat Adeola Oseni ${ }^{5}$, \\ Olufemi Samuel Smith ${ }^{1}$, Medina Bukola Bello ${ }^{1}$
}

${ }^{1}$ Department of Chemical Pathology, Obafemi Awolowo University Teaching Hospital Complex, Ile - Ife, Nigeria

${ }^{2}$ Department of Chemical Pathology, Obafemi Awolowo University, Ile - Ife, Nigeria

${ }^{3}$ Department of Haematology and Immunology, Obafemi Awolowo University, Ile - Ife, Nigeria

${ }^{4}$ Neurology Unit, Department of Medicine, Obafemi Awolowo University, Ile - Ife, Nigeria

${ }^{5}$ Molecular Biology and Genetic Diversity Research Laboratory, Fountain University, Osogbo, Nigeria

*Corresponding Author

Kazeem Adebayo Oderinu

Department of Chemical Pathology, Obafemi Awolowo University Teaching Hospital Complex, Ile - Ife, Nigeria

\begin{abstract}
Introduction: Parkinson's disease is a cause of physical disability and impaired quality of life, and oxidative stress is central in the mechanisms of neural degeneration and cell death in the disease. The aim is to investigate the serum levels and relationship of some cytokines and biomarkers of oxidative stress in patients with Parkinson's disease.

Material and Methods: Forty patients with clinical diagnosis of Parkinson's disease and forty age-and sex-matched apparently healthy controls were recruited for the study. Their venous blood were collected for the estimation of serum Tumour Necrosis Factor-alpha (TNF- $\alpha)$ and Interferon-gamma (IFN- $\gamma)$ by enzyme linked immunosorbent assay method. Serum total antioxidant capacity (TAC) and total oxidative status (TOS) were photo metrically determined.

Results: The study showed that mean serum levels of TNF- $\alpha$ and TOS were significantly higher in patients, while serum TAC levels were significantly lower in the patients. There was a positive correlation between serum TNF- $\alpha$ and IFN- $\gamma$ and both were found to be directly related to serum TOS but not with serum TAC.

Conclusion: The findings from this study suggested that TNF- $\alpha$ increases directly with the TOS levels in patients with Parkinson's disease.

Keywords: Cytokines; Oxidative stress; Parkinson's disease.
\end{abstract}

\section{Introduction}

Parkinson's disease (PD) is the second commonest neurodegenerative disease with a cumulative effect on patients, their families and the healthcare and social care systems. It progresses to cause significant disability and handicap with impaired quality of life for the affected person, and even death. ${ }^{[1]}$ There is increasing evidence that supports the role of central and peripheral inflammation in driving PD initiation and progression. Alterations of the central nervous system environment, for example, by infection or neuronal injury, result in the release of proinflammatory cytokines and reactive 
oxygen species (ROS) thereby contributing to neurodegeneration. ${ }^{[2]}$

In healthy individual, mediators of oxidative stress and inflammation are in balance with the counteracting detoxifying and anti-inflammatory molecules. During disease this balance is shifted towards the oxidative stress and proinflammatory site, leading to DNA and protein damage, inflammation, and finally cell death. ${ }^{[3]}$ In spite of the diversity of the neurodegenerative diseases, oxidative stress and neuroinflammation due to excessive production and release of ROS and proinflammatory cytokines upon mitochondrial injury and dysfunction have been proposed as a general pathological mechanism of all major chronic neurodegenerative diseases including $\mathrm{PD}^{[4]}$

In pathological conditions, astrocytes and mainly microglia release large amounts of TNF- $\alpha$ which is an important component of the so-called neuroinflammatory response that is associated with several neurological disorders. ${ }^{[5]}$ TNF- $\alpha$ has been implicated as an important factor for the onset and perpetuation of neurodegenerative diseases, since increased levels of this cytokine are present in the affected areas in many neurodegenerative diseases. More so, cytokines produced in the brain freely diffuse and pass the blood brain barrier into peripheral blood supply, ${ }^{[6]}$ suggesting associated increased levels of some serum cytokines in the disease. IFN- $\gamma$ can induce both pro and anti-inflammatory responses, and this ability is necessary for a balanced immune response. IFN- $\gamma$ activates microglia and astrocytes and induces inducible nitric oxide synthase (iNOS) expression in CNS. ${ }^{[7]}$ Moreover, it is shown that the levels of IFN- $\gamma$ in CNS are positively correlated with the degree of dopaminergic neuronal degeneration in the diseased monkeys. ${ }^{[8]}$

In all cases of PD, oxidative stress is considered to be the central underlying mechanism that causes cellular abnormalities and death. There are several potential sources including; mitochondrial dysfunction, increased free iron levels and increased dopamine metabolism. ${ }^{[9]}$ The cytokine tumor necrosis factor (TNF), a master regulator of the immune system, plays an important role in the propagation of inflammation due to the activation and recruitment of immune cells via its receptor, TNF receptor 1 (TNFR1). Moreover, TNFR1 can directly induce oxidative stress by the activation of ROS and RNS producing enzymes.

This case-control study assesses the serum levels of TNF- $\alpha$, IFN- $\gamma$, total antioxidant capacity (TAC) and total oxidative status (TOS) in patients with PD attending Obafemi Awolowo University Teaching Hospitals Complex, Ile-Ife, Southwestern Nigeria. Also, the relationships among the measured parameters are determined.

\section{Materials and Methods}

Forty consecutive patients and forty age-and sexmatched controls were investigated. The patients with PD diagnosed by a qualified Neurologist according to the United Kingdom Parkinson Disease Society (UKPDS) brain bank were recruited for the study. The level of severity was determined with the Hoehn and Yahr Staging criteria. The study was conducted with the aid of a proforma to obtain the demographic and clinical data of the participants. People with conditions that can alter or interfere with plasma micronutrient levels such as; liver or renal diseases, cardiac and respiratory disorders, diseases causing malabsorption, intake of vitamin or mineral supplements, active infections, use of thyroid hormones or lithium, artificial metallic body parts and use of psychoactive drugs except for anti-parkinsonism medications were excluded from the study. Ethical approval (Protocol number: ERC/2017/06/17) for this study was obtained from the Ethics and Research Committee of the Obafemi Awolowo University Teaching Hospitals Complex, Ile- Ife.

Ten millilitres of venous blood was collected from each consenting individual from the antecubital vein into plain bottles, serum separated and analysed or stored at $-20^{\circ} \mathrm{C}$ until analysed. Serum TNF-alpha and IFN-gamma were measured with 
immunoassay using a commercially available Enzyme-Linked Immunosorbent Assay kits (Span Biotech Limited, Long gang, Shenzhen). Serum total oxidative status and total antioxidant capacity were photometrically determined using Rel Assay Diagnostics Kits (Gaziantep, Turkey). Data obtained were analyzed and recorded as means $\pm \mathrm{SD}$. Independent $\mathrm{t}$ test was used to test the significant differences in the means obtained, and relationships among the variables were tested using Pearson's correlation coefficient. The $\mathrm{p}$ value less than or equal to 0.05 was taken as significant.

\section{Results}

A total of 40 patients with Parkinson's disease (PD) aged 40 years to 81 years were investigated. Also, 40 age- and sex-matched controls aged 40 years to 82 years were also studied. The patients were made up of 31 males and 9 females representing $77.5 \%$ and $22.5 \%$, respectively, while equal number of male and female controls were also studied. The mean duration of the disease was $3.6 \pm 2.8$ years and the Hoehn and Yahr stage of 1-3. The mean Body Mass Index (BMI) of the patients with PD was $22.01 \pm 3.39$ $\mathrm{kg} / \mathrm{m}^{2}$ while that of the controls was $22.62 \pm 3.17$ $\mathrm{kg} / \mathrm{m}^{2}$, the difference was not statistically significant $(\mathrm{t}=-0.837 ; \mathrm{p}=0.405)$. Also, there was no statistically significant difference between the mean waist circumference of the patients $(82.74 \pm 10.49 \mathrm{~cm})$ and that of the controls $(81.79$ $\pm 1.10 \mathrm{~cm})(\mathrm{t}=0.394, \mathrm{p}=0.695)$.

Table 1 shows the mean $( \pm \mathrm{SD})$ serum levels of tumor necrosis factor-alpha (TNF- $\alpha$ ), interferon gamma (IFN- $\gamma$ ), TAC and TOS. The mean serum TNF- $\alpha(157.90 \pm 30.32 \mathrm{ng} / \mathrm{L} ; 142.46 \pm 16.37 \mathrm{ng} / \mathrm{L})$ and IFN- $\gamma(23.01 \pm 3.13 \mathrm{ng} / \mathrm{ml} ; 22.07 \pm 2.44 \mathrm{ng} / \mathrm{ml})$ concentrations in patients with PD were higher as compared to control values with TNF- $\alpha$ levels being statistically significantly higher. The mean serum concentrations of TOS (8.03 \pm 3.29 $\mu \mathrm{mol} / \mathrm{L} ; 6.24 \pm 1.20 \mu \mathrm{mol} / \mathrm{L})$ was significantly higher in patients with PD compared with controls $(\mathrm{p}=0.004)$. However, mean serum concentration of TAC $(1.69 \pm 0.64 \mathrm{mmol} / \mathrm{L} ; 2.18 \pm 0.51 \mathrm{mmol} / \mathrm{L})$ in PD patients was significantly lower as compared to that of controls $(\mathrm{p}=0.001)$.

Figures 1 to 6 show relationships among serum TNF- $\alpha$, IFN- $\gamma$, TAC and TOS concentrations in patients with PD using Pearson's correlation coefficient. There was moderate positive correlation between serum concentrations of TNF$\alpha$ and that of IFN- $\gamma$ (correlation coefficient ( $\mathrm{r}$ ) = 0.577), the relationship was statistically significant $(\mathrm{p}=0.001)$ (figure 1$)$. There was inverse relationship between serum TNF- $\alpha$ and TAC ( $r=-0.268)$ but it was not statistically significant $(\mathrm{p}=0.095)$ (figure 2$)$. However, there was a significant and strong positive correlation between serum TNF- $\alpha$ concentrations and serum TOS concentrations $(r=0.884, p=-0.001$ ) (figure 3).

The serum concentrations of IFN- $\gamma$ was inversely related with serum TAC concentrations $(\mathrm{r}=$ 0.299) (figures 4), the correlation was not statistically significant $(\mathrm{p}=0.061)$. However, the relationship between serum concentrations of IFN- $\gamma$ and serum TOS concentrations was direct (figure 5), the correlation was statistically significant $(r=0.677, p=0.001)$. There was significant inverse correlation between serum concentrations of TAC and TOS in patients with $\mathrm{PD}(\mathrm{r}=-0.487, \mathrm{p}=0.001)$ (figure 6$)$.

Table 1: Mean Serum TNF- $\alpha$, IFN- $\gamma$, TAC and TOS in study population

\begin{tabular}{lcccc}
\hline ANALYTES & $\begin{array}{c}\text { PD PATIENTS } \\
(\mathbf{n}=\mathbf{4 0})\end{array}$ & $\begin{array}{c}\text { CONTROLS } \\
(\mathbf{n = 4 0 )} \\
\text { MEAN } \pm \text { SD }\end{array}$ & $\begin{array}{c}\text { MEAN } \pm \text { SD } \\
\text { t-test }\end{array}$ & p-value \\
\hline TNF- $\boldsymbol{\alpha}(\mathbf{n g} / \mathbf{L})$ & $157.90 \pm 30.32$ & $142.46 \pm 16.37$ & 2.65 & \\
IFN- $\boldsymbol{\gamma}(\mathbf{n g} / \mathbf{m l})$ & $23.01 \pm 3.13$ & $22.07 \pm 2.44$ & 1.49 & 0.139 \\
TAC $(\mathbf{m m o l} / \mathbf{L})$ & $1.69 \pm 0.64$ & $2.18 \pm 0.51$ & -3.79 & $<\mathbf{0 . 0 0 1}$ \\
TOS $(\boldsymbol{\mu m o l} / \mathbf{L})$ & $8.03 \pm 3.29$ & $6.24 \pm 1.20$ & 2.94 & $\mathbf{0 . 0 0 4}$ \\
\hline
\end{tabular}

Significant $\mathrm{p}$ - values are written in bold fonts. TNF- $\alpha$ - Tumour Necrosis Factor-alpha, IFN- $\gamma$ - Interferon-gamma, TAC- Total antioxidant capacity, TOS- Total oxidative status, PD- Parkinson's disease. 


\section{JMSCR Vol||07||Issue |08||Page 505-513||August}

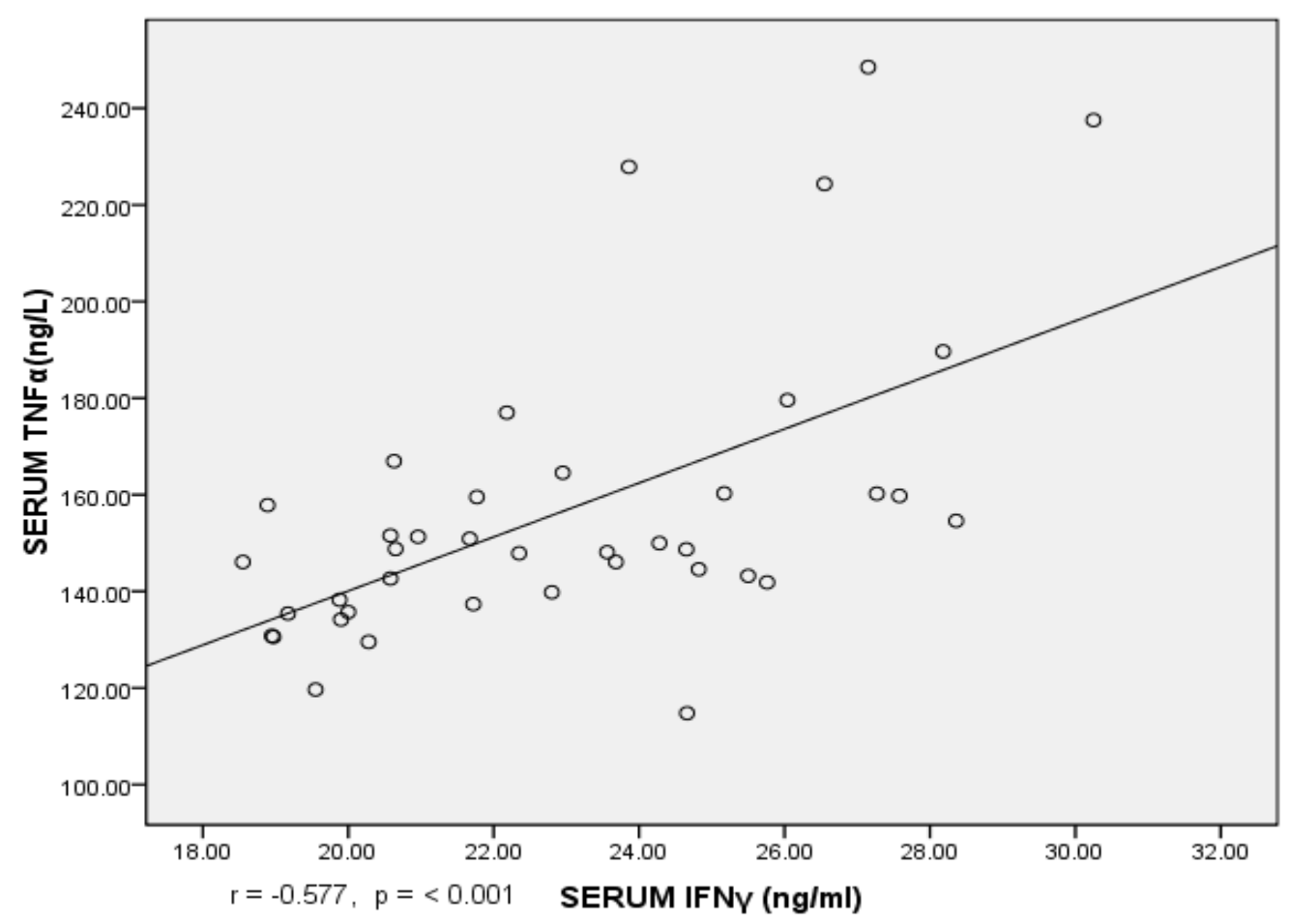

Figure 1: Correlation between Serum TNF- $\alpha$ and IFN- $\gamma$ Concentrations in PD Patients

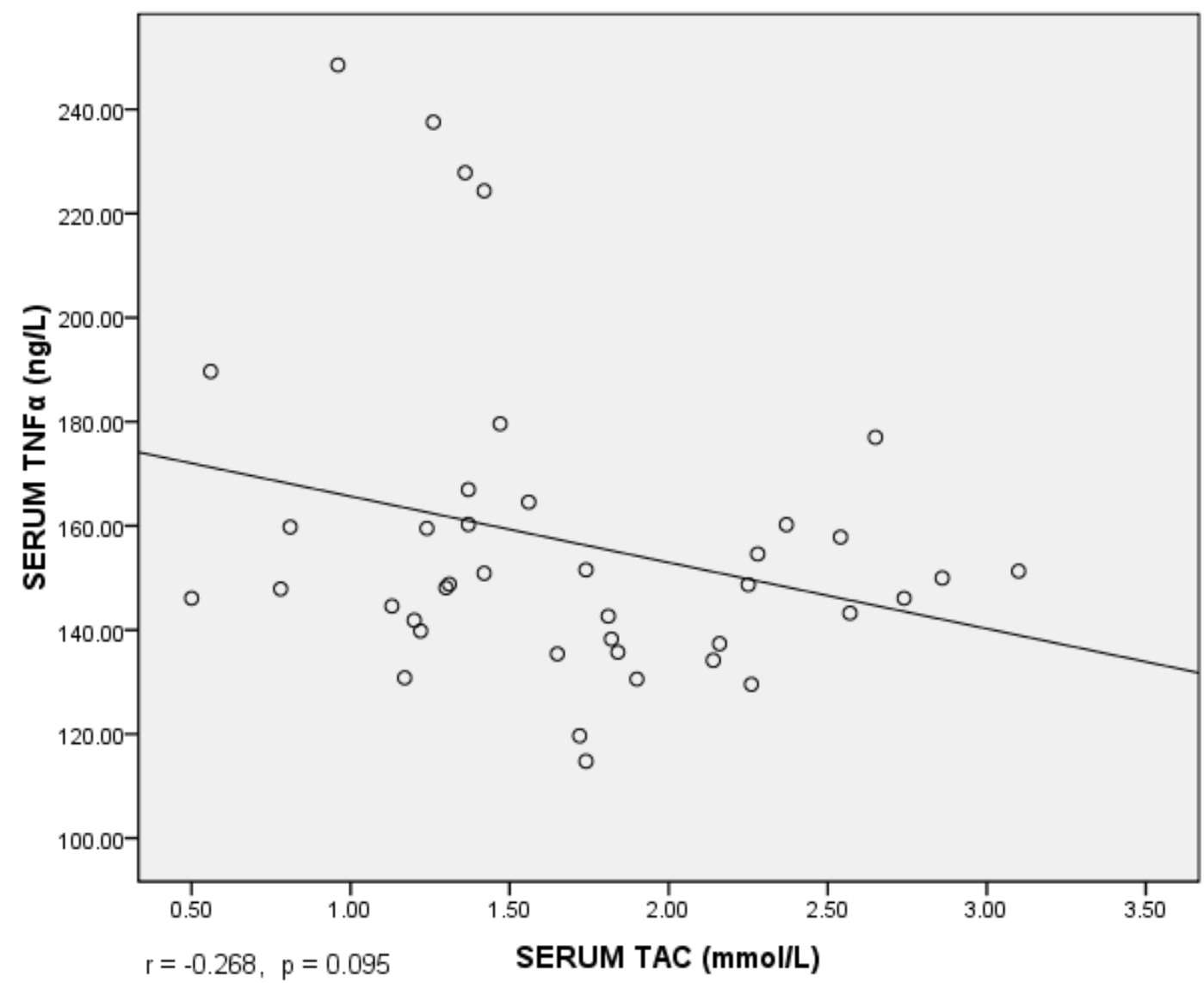

Figure 2: Correlation between Serum Concentrations of TNF- $\alpha$ and TAC in PD Patients. 


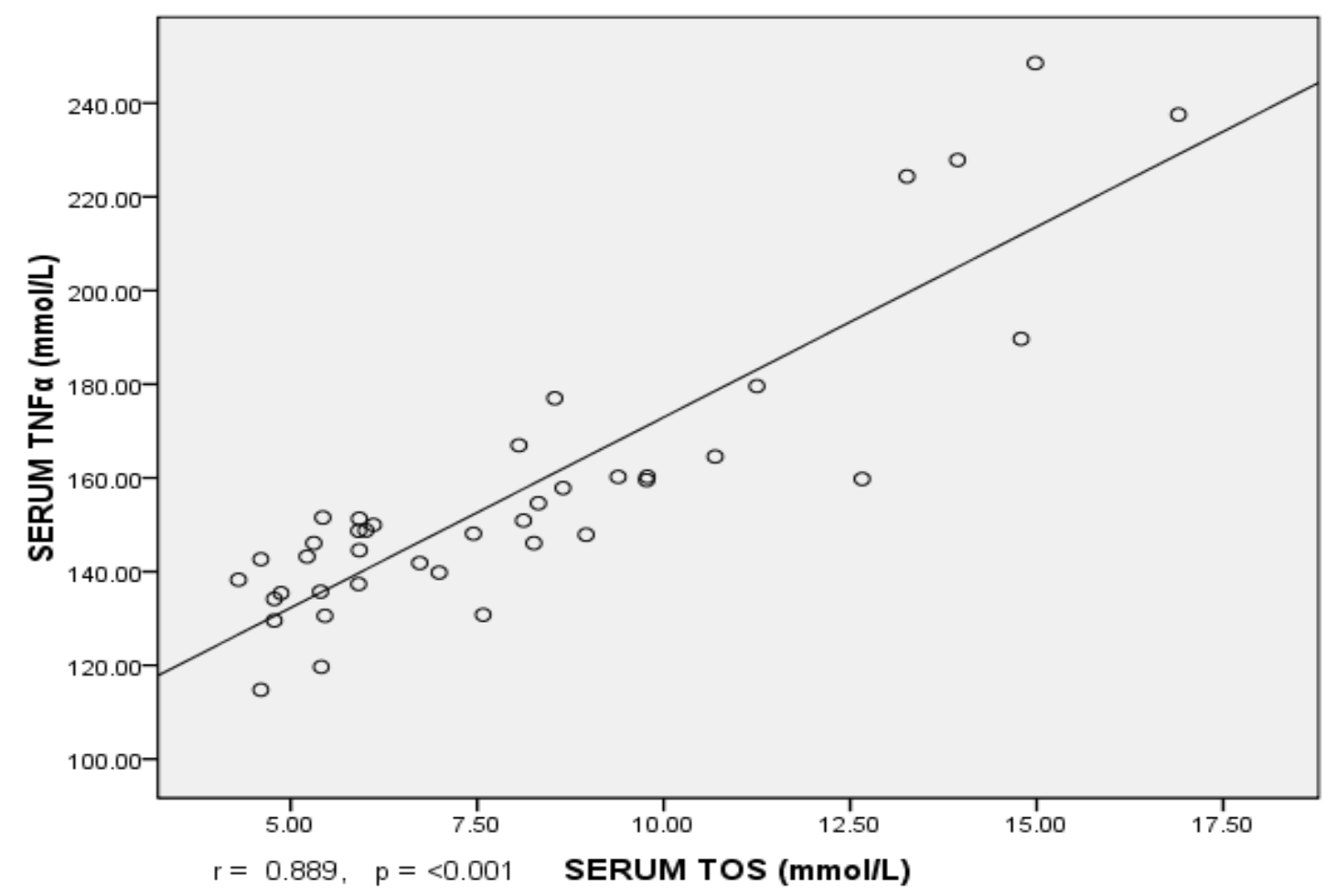

Figure 3: Correlation between Serum Concentrations of TNF- $\alpha$ and TOS in PD Patients

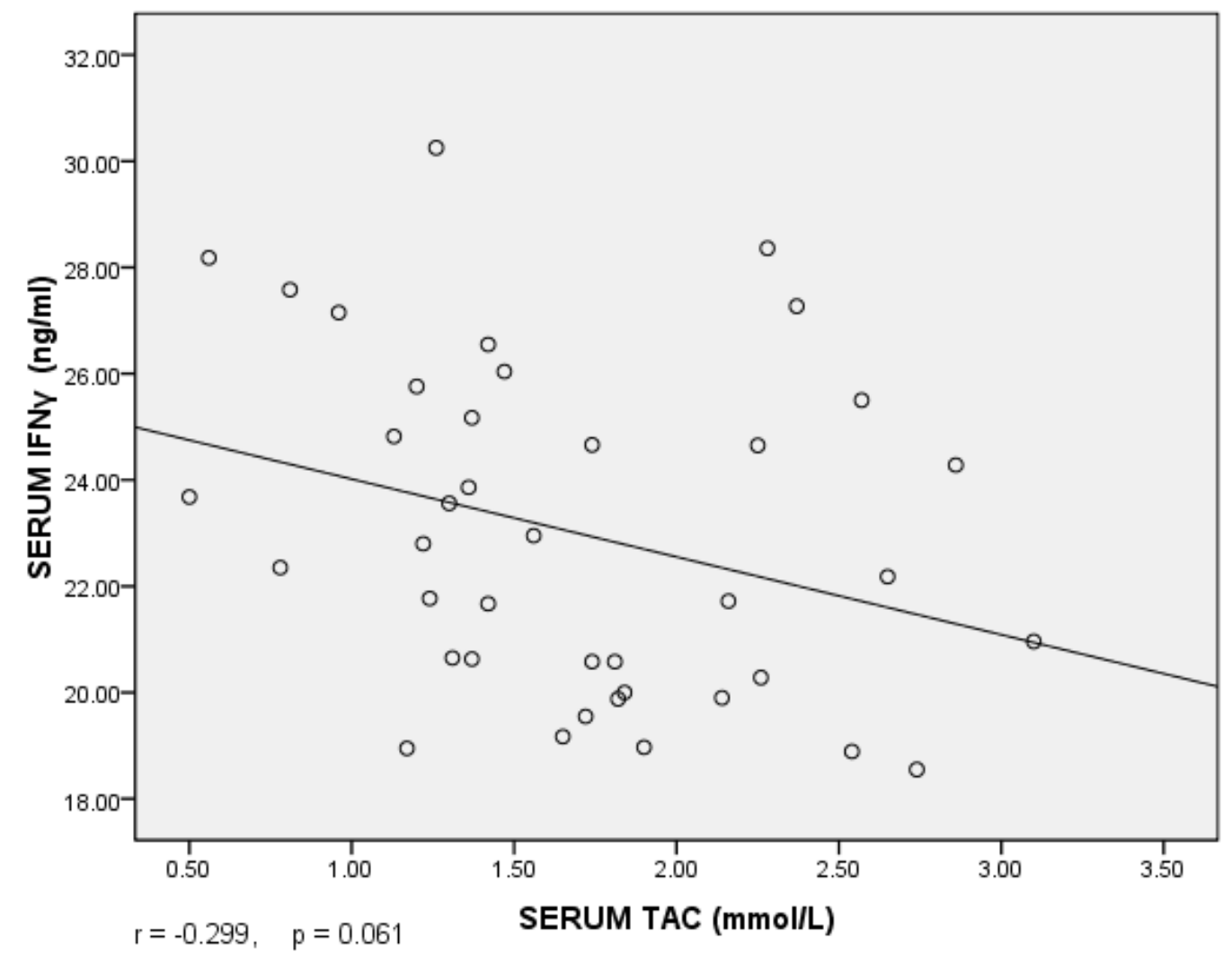

Figure 4: Correlation between Serum Concentrations of IFN- $\gamma$ and TAC in PD Patients 


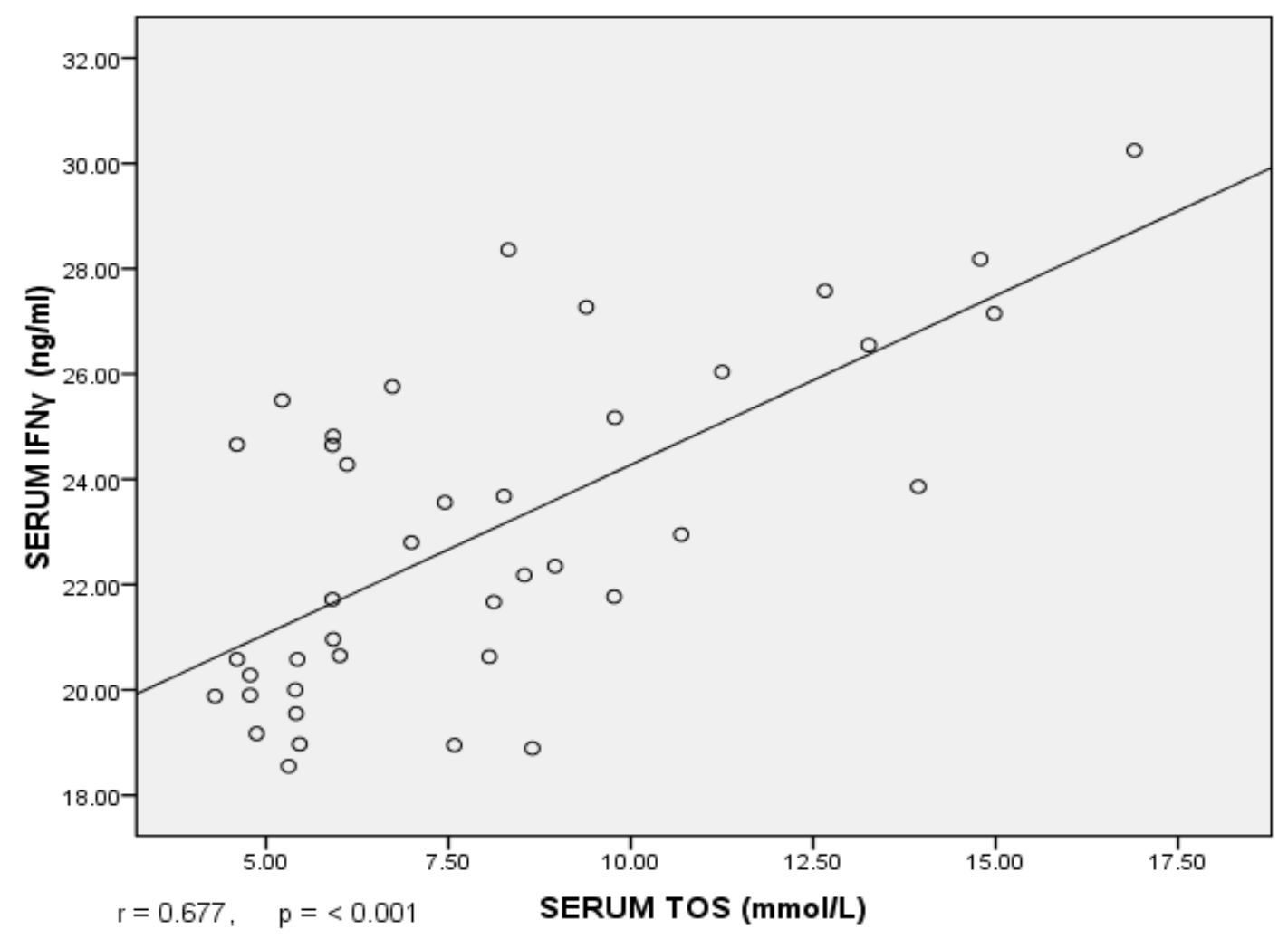

Figure 5: Correlation between Serum Concentrations of IFN- $\gamma(\mathrm{ng} / \mathrm{ml})$ and TOS (mmol/L) in PD Patients.

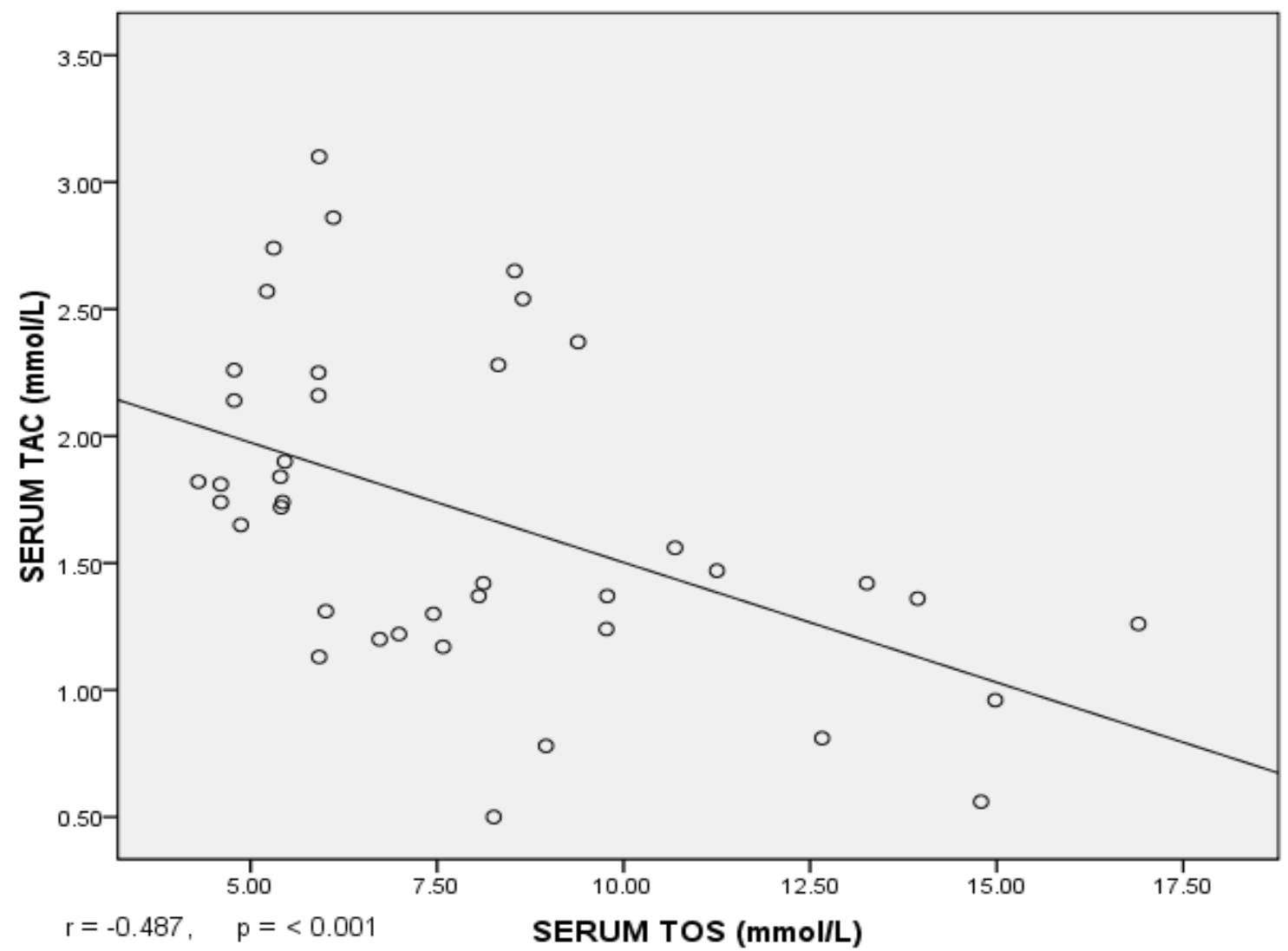

Figure 6: Correlation between Serum Concentrations of TAC and TOS in PD Patients 


\section{Discussion}

The result of this study found a significant increase in the serum levels of tumour necrosis factor alpha (TNF- $\alpha)$ in patients with PD as compared to that of healthy controls. This is in agreement with other studies. ${ }^{[10,11]}$ However, Gupta et al found a decrease in serum level of TNF- $\alpha$ in PD compared with that of controls. ${ }^{[12]} \mathrm{A}$ similar case control study in southern Sweden showed no significant difference between the serum levels of TNF- $\alpha$ in PD and controls. ${ }^{[13]}$ Lindqvist and colleagues ${ }^{[13]}$ recruited less than half of the number of the patients for controls which might affect the statistical inference. Also, the findings of Gupta et al in India stated that the mean serum concentrations of TNF- $\alpha$ in patients and controls were $45.67 \pm 24.69 \mathrm{pg} / \mathrm{ml}$ and 638.25 $\pm 511.02 \mathrm{pg} / \mathrm{ml}$ respectively. The distribution of TNF- $\alpha$ concentration in their controls was too dispersed, evidenced by the standard deviation of 511.02 and the differences in the values of patients and controls. Therefore, some of their controls might have inflammatory disease that could have accounted for the very high levels of serum TNF- $\alpha$ found in them.

This study observed insignificant higher level of serum IFN- $\gamma$ in PD patients than that of the controls. This is consistent with the findings of Qin et $\mathrm{al}^{[14]}$ and Eidson et al. ${ }^{11}$ In contrast, Brodacki et al ${ }^{[10]}$ observed increase in serum IFN$\gamma$ of PD patients compared with the controls while Gruden et $\mathrm{al}^{[15]}$ noticed decrease in serum IFN- $\gamma$. In an experimental animal PD model, the TNF- $\alpha$ was increased but there was insignificant difference in levels of IFN- $\gamma .{ }^{[16]}$ Also, an observation of increased cognitive decline in PD has been associated with increased serum TNF levels due to systemic inflammation. ${ }^{[17]}$

Furthermore, there was direct correlation between the serum TNF- $\alpha$ and IFN- $\gamma$ in patients with PD in this study. The IFN- $\gamma$ induces TNF- $\alpha$ gene expression, and it activates TNF- $\alpha$ production and release in microglia. ${ }^{[14,18]}$ Qin and colleagues revealed that the entry of IFN- $\gamma$ to the brain induced the activation of microglia and subsequent production of more inflammatory factors, which may then cause neuronal death. ${ }^{[14]}$ Cytokines activation and neuroinflammation were implicated to have deleterious effects on the dopaminergic system and as principal factors contributing to PD progression. ${ }^{[6]}$ Brodacki et al showed that the pro-inflammatory and antiinflammatory factors are higher in PD patients suggesting a strong relationship between systemic inflammation and immune responses and PD. ${ }^{[10]}$ Epidemiologic findings revealed that prior long term nonsteroidal anti-inflammatory drug (NSAID) use was associated with a lower PD risk. ${ }^{[19]}$ This suggests that peripheral inflammation may influence the neuroinflammation, hence contributing to the PD pathogenesis.

This study also observed that oxidative stress was incurred in the patients as indicated by the statistically significant increase of serum total oxidative status (TOS) in PD patients as compared to controls. At the same time, the serum total antioxidant capacity (TAC) was found to be significantly lower in the PD patients than the controls. In agreement to this result, the available literature reported similar findings. ${ }^{[20]}$ TOS is a measure of levels of ROS and/or RNS. This implies that ROS and/or RNS in form of superoxide anion radical, hydroxyl radical $(\mathrm{OH})$, hydrogen peroxide $\left(\mathrm{H}_{2} \mathrm{O}_{2}\right)$, nitric oxide $(\mathrm{NO})$, nitrogen dioxide $\left(\mathrm{NO}_{2}\right)$ and/or dinitrogen trioxide $\left(\mathrm{N}_{2} \mathrm{O}_{3}\right)$ might be elevated in PD patients. In contrast, the antioxidant molecules (TAC) in the form of enzymes; superoxide dismutase, glutathione peroxidase, catalase and nonenzymatic antioxidant vitamins like vitamin $\mathrm{E}$ and might be decreased in serum of patients with PD.

In human patients and experimental models for PD, oxidative stress has been shown to have a significant pathogenic role in the selective loss of dopaminergic neurons. ${ }^{[6]}$ Oxidative stress causes direct cellular damages and also activates signaling pathways leading to cell death. ${ }^{[4]}$ Oxidative stress is also implicated in the neuroinflammation and protein aggregation due to the action of ROS in the course of the disease. ${ }^{[3]}$ 
Activated microglia and astrocyte produce reactive oxygen species (ROS), which contribute to neurodegeneration. ${ }^{[2,14]}$ More so, the findings in this study showed that serum TNF- $\alpha$ and IFN- $\gamma$ were directly related with Total Oxidative Status (TOS) but were not related with Total Antioxidant Capacity (TAC) levels. This shows that ROS and RNS were dependent on TNF- $\alpha$ and/or IFN- $\gamma$, or vice versa.

However, TNF- $\alpha$ and IFN- $\gamma$ had no significant relationship with the antioxidant molecules. The common features in PD are permanent activation of microglia and thus in constant release of proinflammatory cytokines and ROS. ${ }^{[3,7]}$ IFN- $\gamma$ is a potent inducer of activation of microglia. ${ }^{[7]}$ The activated microglia produces TNF- $\alpha$ and TOS. ${ }^{[2,3 \text {, }}$

5] TNF- $\alpha$ and IFN- $\gamma$ increase the expression of inducible nitric oxide synthase (iNOS) resulting in protein oxidation and nitration, thereby causing the death of the neurons. ${ }^{[3]}$ TNF- $\alpha$ can directly stimulate the formation of ROS by activating NADPH oxidases thus inducing the production of superoxide. ${ }^{[3,5]}$ Hence, TNF- $\alpha$ has a contributive role in the pathogenesis and / or clinical course of PD. Therefore, it is not surprising that TNF- $\alpha$ specific inhibitors as potential novel drugs show promise for the treatment of PD.

\section{Conclusion}

The findings in this study show that serum cytokines mainly TNF- $\alpha$ are interrelated with oxidants, and the serum TNF- $\alpha$ and TOS are significantly increased in PD patients. However, the serum antioxidants are low and are independent of TNF- $\alpha$ and IFN- $\gamma$. Further research, more importantly, longitudinal study on the role of immune system and oxidative stress in the pathogenesis and/or clinical course of PD is required.

\section{Acknowledgment}

This study was self - funded and there is no conflict of interest among authors.

\section{References}

1. Farombi TH, Owolabi MO, Oguniyi A. Falls and their associated risks in Parkinson's disease patients in Nigeria. J Mov Disord. 2016;9(3):160-5.

2. Amor S, Puentes F, Baker D, van der Valk P. Inflammation in neurodegenerative diseases. Immunology. 2010;129(2):15469.

3. Fischer R, Maier $O$. Interrelation of oxidative stress and inflammation in neurodegenerative disease: role of TNF. Oxid Med Cell Longev. 2015;2015: 610813 .doi: 10. 1155/2015/610813.

4. Emerit J, Edeas $M$, Bricaire $F$. Neurodegenerative diseases and oxidative stress. Biomed and Pharmacother. 2004;58(1):39-46.

5. Montgomery SL, Bowers WJ. Tumor necrosis factor-alpha and the roles it plays in homeostatic and degenerative processes within the central nervous system. J Neuroimmune Pharmacol. 2012;7(1):4259.

6. Sadek HL, Almohari SF, Renno WM. The inflammatory cytokines in the pathogenesis of Parkinson's disease. J Alzheimers Dis Parkinsonism. 2014;4:148. doi:10.4172/2161-0460.1000148

7. Jung JS, Kim DH, Kim HS. Ginsenoside Rh1 suppresses inducible nitric oxide synthase gene expression in IFN-gammastimulated microglia via modulation of JAK/STAT and ERK signaling pathways. Biochem Biophys Res Commun. 2010;397(2):323-8.

8. Lin F, Young HA. The talented interferongamma. Advances in Bioscience and Biotechnology. 2013;4: 6 - 13. doi:10.4236/abb.2013.47A3002

9. Moore DJ, West AB, Dawson VL, Dawson TM. Molecular pathophysiology of Parkinson's disease. Annu Rev Neurosci. 2005;28:57 - 87. 
10. Brodacki B, Staszewski J, Toczylowska B, Kozlowska E, Drela N, Chalimoniuk M, Stepien A. Serum interleukin (IL-2, IL-10, IL-6, IL-4), TNFalpha, and INFgamma concentrations are elevated in patients with atypical and idiopathic parkinsonism Neurosci Lett. 2008;441(2):158-62.

11. Eidson LN, Kannarkat GT, Barnum CJ, Chang J, Chung J, Caspell-Garcia C, Taylor P, Mollenhauer B, Schlossmacher MG, Ereshefsky L, Yen M, Kopil C, Frasier M, Marek K, Hertzberg VS, Tansey MG. Candidate inflammatory biomarkers display unique relationships with alpha-synuclein and correlate with measures of disease severity in subjects with Parkinson's disease. J Neuroinflammation. 2017;14(1):164. doi: 10.1186/s12974-017-0935-1.

12. Gupta V, Garg RK, Khattri S. Levels of IL-8 and TNF-alpha decrease in Parkinson's disease. Neurol Res. 2016;38(2):98-102.

13. Lindqvist D, Kaufman E, Brundin L, Hall S, Surova Y, Hansson O. Non-motor symptoms in patients with Parkinson's disease-correlations with inflammatory cytokines in serum. PLoS One. 2012;7(10):e47387. doi:10.1371/journal.pone.0047387.

14. Qin L, Wu X, Block ML, Liu Y, Breese GR, Hong JS, Knapp DJ, Crews FT. Systemic LPS causes chronic neuroinflammation and progressive neurodegeneration. Glia. 2007;55(5):453-62.

15. Gruden MA, Yanamandra K, Kucheryanu VG, Bocharova OR, Sherstnev VV, Morozova-Roche LA, Sewell RD . Correlation between protective immunity to alpha-synuclein aggregates, oxidative stress and inflammation. Neuroimmunomodulation. 2012;19(6):334-42.
16. McGeer PL, McGeer EG. Inflammation and neurodegeneration in Parkinson's Disease. Parkisonism Relat Disord. 2004;10(1):S3-7.

17. Holmes C, Cunningham C, Zotova E, Woolford J, Dean C, Kerr S, Culliford D, Perry VH. Systemic inflammation and disease progression in Alzheimer disease. Neurology. 2009;73(10):768-74.

18. Welser-Alves JV, Milner R. Microglia are the major source of TNF-alpha and TGFbeta1 in postnatal glial cultures, regulation by cytokines, lipopolysaccharide, and vitronectin. Neurochem Int. 2013;63(1): 47-53.

19. Chen H, O'Reilly EJ, Schwarzschild MA, Ascherio A. Peripheral inflammatory biomarkers and risk of Parkinson's disease. Am J Epidemiol. 2008;167(1):905.

20. Forte G, Alimonti A, Pino A, Stanzione P, Brescianini S, Brusa L, Sancesario G, Violante N, Bocca B. Metals and oxidative stress in patients with Parkinson's disease. Ann 1st Super Sanita. 2005;41(2):189 - 95. 